\title{
Serial Micropuncture Analysis of Glomerular Function in Two Rat Models of Glomerular Sclerosis
}

\author{
Agnes Fogo, Yoshiyuki Yoshida, Alan D. Glick, Toshio Homma, and lekuni Ichikawa \\ Departments of Pediatrics and Pathology, Vanderbilt University School of Medicine, Nashville, Tennessee 37232
}

\begin{abstract}
We have recently developed a micropuncture technique to assess repeatedly function of the same nephrons in chronic renal disease and subsequently examine the morphology of their glomeruli by serial thin-section histological analysis. Using this approach, a potential causal linkage between early functional patterns and late structural abnormalities was examined in glomeruli of two established rat models of glomerular sclerosis. The models are $(a)$ puromycin aminonucleoside (PAN) administration in unilaterally nephrectomized Munich-Wistar rats and (b) adriamycin (ADM) treatment in nonnephrectomized Munich-Wistar rats. Single nephron GFR (SNGFR) and glomerular capillary hydraulic pressure $\left(\boldsymbol{P}_{\mathrm{GC}}\right)$ were measured repeatedly for 8 (PAN rats) or 31 wk (ADM rats). In all animals studied, values for $\mathbf{P}_{\mathrm{GC}}$ remained at, or slightly below, levels measured before PAN or ADM administration. SNGFR values declined progressively in all glomeruli in PAN rats. Although some glomeruli in ADM rats had an increase in SNGFR above levels observed in nonnephrectomized control rats, these hyperfiltering glomeruli did not have abnormally high $\boldsymbol{P}_{\mathrm{GC}}$ nor did they exhibit glomerular sclerosis at the completion of the study. Histological analysis revealed the existence of a significant inverse correlation between the degree of sclerosis and SNGFR assessed at the time of sacrifice in both PAN and ADM groups. Chronic administration of captopril, an angiotensin I converting enzyme inhibitor, in PAN rats substantially attenuated development of glomerular sclerosis without affecting $\boldsymbol{P}_{\mathrm{GC}}$ in earlier stages. The observations in these models indicate that glomerular hyperfiltration and hypertension are not required for the development of glomerular sclerosis in renal diseases, and angiotensin I converting enzyme inhibitor can exert its protective effect independently of its effect on glomerular capillary pressure.
\end{abstract}

\section{Introduction}

Puromycin aminonucleoside, or PAN, ${ }^{1}$ is perhaps one of the most widely used agents in the study of experimental renal

Presented in part at the Annual Meeting of the American Society of Nephrology, Washington, DC, 8 December 1986, and published in abstract form (1987. Kidney Int. 31:384.)

Address reprint requests to Dr. Ichikawa, Division of Pediatric Nephrology, Vanderbilt University Medical Center, C-4204 Medical Center North, 21 st and Garland Avenue, Nashville, TN 37232.

Received for publication 14 May 1987 and in revised form 8 February 1988.

1. Abbreviations used in this paper: ACE, angiotensin I converting enzyme; ADM, adriamycin; ANOVA, analysis of variance; CEI, con-

J. Clin. Invest.

(c) The American Society for Clinical Investigation, Inc.

0021-9738/88/07/0322/09 \$2.00

Volume 82 , July $1988,322-330$ disease. Shortly after administration, animals given PAN develop glomerular lesions that are indistinguishable ultrastructurally and biochemically from human minimal change disease (1-12). Investigators $(12,13)$ have also noted that, when animals are treated chronically with PAN, progressive azotemia and glomerular lesions develop that remarkably resemble the mesangial expansion and glomerular sclerosis seen in a variety of human chronic renal diseases. Adriamycin (ADM) given acutely $(14,15)$ or chronically $(16)$, has been shown to have glomerular pathogenic effects virtually identical to those of PAN, although its chemical structure is different. Previous studies by us (17) and others (15) described in detail the glomerular functional pattern during the acute stage in these PAN- and ADM-treated experimental models. In those studies, reduced glomerular perfusion and filtration were noted uniformly in all nephrons in the early stage of disease.

This is in marked contrast to the pattern seen in some other experimental animal models in which glomerular sclerosis also develops chronically. Thus, the model of subtotal ablation of renal mass is characterized by a marked hyperperfusion and hyperfiltration in remnant nephrons in the early stage before development of highly focal glomerular sclerotic lesions (18). The rat model of diabetes mellitus induced by streptozotocin, although requiring many more weeks before abnormal histology becomes discernible, has also been shown to have abnormally high glomerular capillary pressure and filtration during its early stages (19). These experimental observations have since been extrapolated and have led to theories that glomerular hyperfunction may be the common pathway present at early stages, and may play an essential role in the development of glomerular sclerosis in chronic renal diseases. Since the patterns of glomerular sclerosis that develop following PAN or ADM administration are also focal in nature $(13,16)$, we suspected that those selected glomeruli in which structural abnormalities develop may represent a specific subpopulation of glomeruli, which are hypoperfused and hypofiltering initially but, unlike the other nephrons, soon become hyperfunctioning. In designing the present studies, we felt it essential, in view of the focal nature of the glomerular sclerosis in the chronic PAN and ADM models, to perform functional assessment (in early stage) and histological examination (in late stage) on the same single glomeruli. In addition, periodical monitoring of the function of these glomeruli throughout the duration of study appeared to be indicated, since the hypothesized transition from hypo- to hyperfunction in the ultimately sclerosed glomeruli might take place in an unpredictable time period. The methodology of serial micropuncture measurements developed by us recently (20) allowed us to accomplish both of these goals. As discussed in detail elsewhere (20) vigorous vali-

verting enzyme inhibitor; $K_{f}$, ultrafiltration coefficient; MAP, mean arterial pressure; PAN, puromycin aminonucleoside; $\boldsymbol{P}_{\mathrm{BS}}$, Bowman's space hydraulic pressure; $P_{\mathrm{GC}}$, glomerular capillary hydraulic pressure; SAP, systolic arterial pressure; SNGFR, single nephron GFR; $U_{\text {prot }} V$, urinary protein excretion. 
dation tests have confirmed that the serial micropuncture procedures per se do not affect subsequent glomerular function or histology (at least at the light microscopic level) of the glomeruli subjected to functional assessment. The segmental glomerular lesions were studied by light microscopic serial section analysis, allowing semiquantitation of the degree of sclerosis of the whole glomerulus. By using these new techniques, we explored a causal linkage between functional pattern and structural changes within the same glomeruli in the chronic PAN and ADM rat models.

\section{Methods}

\section{General}

Experiments were performed on 49 adult Munich-Wistar rats. Experimental groups were PAN-treated rats (group I), control for PAN rats (group II), PAN-treated rats with converting enzyme inhibitor (CEI) (group III), ADM-treated rats (group IV) and control for ADM rats (group V). All animals were allowed free access to regular rat chow and tap water throughout the study except for $\sim 15 \mathrm{~h}$ before each micropuncture measurement when the animals were allowed water only. Blood samples were taken periodically from tail veins of awake rats to measure blood urea nitrogen (BUN). 12-h urinary collection was performed in metabolic cages periodically, and urinary protein concentration was measured. Systolic arterial pressure (SAP) was measured in anesthesized rats by the tail cuff method (21) immediately before and after micropuncture experiments, and also periodically in awake rats. During the procedures of unilateral nephrectomy, mapping of surface glomeruli or serial micropuncture procedures specified below, animals were anesthetized with sodium pentobarbital (Nembutal; Abbott Laboratories, North Chicago, IL, $25-30 \mathrm{mg} / \mathrm{kg}$ body wt, i.p.), with the exception of the final micropuncture measurements, and placed on a temperature-regulated table. All surgical instruments were sterilized with $70 \%$ ethyl alcohol. After each micropuncture procedure except during the final assessment, the abdominal incision was closed with 3-0 silk (Ethicon, Inc., Somerville, NJ), and $10,000 \mathrm{U}$ of penicillin $\mathrm{G}$ (Wyeth Laboratories Inc., Philadelphia, PA) was injected subcutaneously. The rats were returned to their cages after recovering from anesthesia. At the final micropuncture measurements, animals were anesthetized with Inactin (Byk, FRG; $100 \mathrm{mg} / \mathrm{kg}$ body wt, i.p.). Micropuncture assessment, mean systemic arterial pressure (MAP) from left femoral artery and whole kidney GFR measurement were followed by marking of glomeruli (specified below), and animals were sacrificed for histological studies.

\section{Serial micropuncture measurements}

Mapping of surface glomeruli and measurements of single nephron glomerular filtration rate (SNGFR), glomerular capillary hydraulic pressure $\left(P_{\mathrm{GC}}\right)$, and Bowman's space hydraulic pressure $\left(\boldsymbol{P}_{\mathrm{BS}}\right)$ were performed in hydropenic rats as described elsewhere in detail (20). Briefly, surface glomeruli and the earliest segment of proximal tubules originating from these glomeruli were identified by injecting a small quantity of $0.1 \%$ lissamine green into proximal convolutions in the vicinity of surface glomeruli in a retrograde manner. Geographical localization of the specific glomeruli was recorded by Polaroid photographs and sketches of the closest proximal tubule convolutions. These glomeruli could then be identified by these topographical maps in subsequent micropuncture studies. Precisely timed (1-2 min) fluid samples were collected from the earliest segment of proximal tubules previously identified for determination of SNGFR. $P_{\mathrm{GC}}$ and $P_{\mathrm{BS}}$ were measured with a continuous recording, servo-nulling pressure system (model 4A; Instrumentation for Physiology and Medicine, San Diego, CA) only in nephrons from which samples of proximal fluid were not obtained. Hydraulic output from the servo-null system was coupled electronically to a channel of the direct-writing recorder (recorder 2400S; Gould Inc., Cleveland, $\mathrm{OH}$ ) by means of a pressure transducer.
SNGFR and $P_{\mathrm{GC}} / P_{\mathrm{BS}}$ measurements were done on an average of 5.3 and 3.1 glomeruli per kidney, respectively. At the completion of the final micropuncture measurements, surface glomeruli on which micropuncture measurements were performed were marked by injecting a small volume of dye (The Davidson Marking System; Bradley Products, Inc., Bloomington, MN), into the subcapsular space just above, and/or into Bowman's space of the surface glomerulus. This dye served to identify specific glomeruli for the subsequent histological study.

The above serial micropuncture methodology and the validation of the technique are discussed in length elsewhere (20). The tests of validation indicated: (a) Serial micropuncture per se does not cause structural injury at the light microscopic level, nor are hemodynamic parameters altered by the procedure. $(b)$ Earliest proximal tubule flow rate gives highly reproducible estimates for SNGFR. (c) SNGFR was lower in hydropenia vs. euvolemia, but within a given kidney the order of glomerular rank for SNGFR remained unaffected, while $P_{\mathrm{GC}}$ values were not affected by the hydropenic condition.

\section{Histological study}

Light microscopic examination was performed after the completion of the micropuncture studies. The kidneys were removed and immersion fixed in $10 \%$ neutral buffered formalin after marking of the glomeruli, which had been subjected to micropuncture assessment. This allowed for gross visualization of the site of the specific glomerulus studied during embedding and processing. Serial sections ( $3 \mu \mathrm{m}$ thick) were made and stained with periodic acid Schiff. A semiquantitative score (sclerosis index) was used for assessing glomerular sclerosis by the method of Raij, Azar, and Keane (22). Each glomerulus was evaluated by a minimum of 10 sections representing an even distribution throughout the glomerulus. On each section, sclerosis was graded from 0 to 4 . Grade 0 is $0 \%$ sclerosis; grade 1 is sclerosis of up to $25 \%$ of the glomerulus; grade 2 is $26-50 \%$ sclerosis; grade 3 is $51-75 \%$ sclerosis and grade 4 is $76-100 \%$ sclerosis of the glomerulus. The average of the scores from all sections of a given glomerulus was calculated to obtain the sclerosis index for the single glomerulus. A whole kidney sclerosis index was obtained by averaging scores for all glomeruli on a single thin section, with a minimum of $\mathbf{5 0}$ glomeruli analyzed.

\section{Experimental groups}

Group I (PAN-treated rats, $n=9$ ). The experimental protocol for group I animals is outlined in Fig. $1 \mathrm{~A}$. In 6 rats, mapping of surface glomeruli was followed by right unilateral nephrectomy. 2 wk later, initial micropuncture measurements were performed. On the following day, the

B
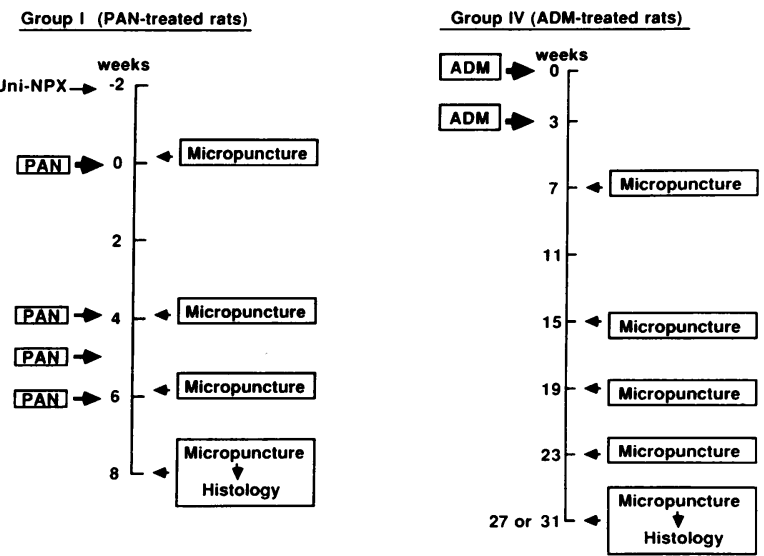

Figure 1. Schematic presentation of the experimental protocols for the group I $(A)$ and group IV $(B)$ studies. In this and the other figures, PAN and ADM stand for puromycin aminonucleoside (intraperitoneal injection) and adriamycin (intravenous injection), respectively. Uni-NPX stands for unilateral nephrectomy. 
first dose of PAN i.p. (Sigma Chemical Co., St. Louis, MO; $10 \mathrm{mg} / 100$ $\mathrm{g}$ body $\mathrm{wt}$ ) was given. Additional PAN injections of $4 \mathrm{mg} / 100 \mathrm{~g}$ body wt i.p. were given at 4-6 wk after the first injection, i.e., a modification of the protocol described by Glasser et al. (13). Micropuncture measurements were repeated more than twice at 4,6 , and $8 \mathrm{wk}$ after the initial PAN administration, and animals were killed after marking of surface glomeruli at $8 \mathrm{wk}$. In two of the six rats, micropuncture measurements were not performed before the initial PAN administration. Group I includes three additional animals that were micropunctured only once $8 \mathrm{wk}$ after the initial PAN administration. One rat died $7 \mathrm{wk}$ after the initial PAN administration, so histological study was done in the remaining eight animals.

Group II (control rats for PAN treatment, $n=7$ ). Seven rats underwent the same protocol (i.e., right unilateral nephrectomy) as in group I except that saline was injected intraperitoneally instead of PAN.

Group III (PAN plus CEI-treated rats, $n=8$ ). Experiments were performed in five rats in a manner identical to that of group I. However, these animals were given water containing CEI ( $50 \mathrm{mg}$ of captopril; E. R. Squibb \& Sons, Inc., Princeton, NJ) per $100 \mathrm{ml} \mathrm{ad} \mathrm{lib.} \mathrm{on} \mathrm{the}$ day of the right nephrectomy and throughout the rest of the study. Three additional animals were studied to evaluate the histology of the whole kidney without serial micropuncture measurements being performed.

Group IV (ADM-treated rats, $n=7)$. The protocol for group IV is summarized in Fig. $1 \mathrm{~B}$ : Seven rats were given ADM intravenously (doxorubicin hydrochloride; Sigma Chemical Co., St. Louis, MO, 0.2 $\mathrm{mg} / 100 \mathrm{~g}$ body $\mathrm{wt}$ ) twice with a 3-wk interval (16). Mapping of surface glomeruli was followed by initial micropuncture measurements. Micropuncture measurements were repeated more than three times at 7 , $15,19,23,27$, and/or 31 wk after the first ADM administration. At the 27 th or 31 st week, final micropuncture measurements were followed by marking of surface glomeruli, and animals were killed for histological study.

Group V (control rats for ADM treatment, $n=18$ ). 18 age-matched nonnephrectomized animals (three subgroups containing six rats each) were used as controls for ADM-treated rats. Mapping of surface glo- meruli and micropuncture measurements were performed once in each of these three subgroups of six age-matched rats at $7,15-19$, or 27-31 wk.

\section{Analytic}

BUN was measured using a BUN analyzer (BUN Analyzer II; Beckman Instruments, Inc., Fullerton, CA). Plasma and urine concentration of inulin for the determination of whole kidney GFR was assessed by the anthrone method (23). Urine protein concentration was measured by the Coomassie Brilliant Blue method (24). The fluid collected from the earliest segment of proximal tubules was processed for the determination of SNGFR as described in detail elsewhere (20).

\section{Statistical methods}

Results are expressed as mean \pm 1 SE. Nonparametric data from multiple groups were tested using the Kruskall-Wallis one-way analysis of variance (ANOVA) with subsequent Mann-Whitney $U$ test if the ANOVA indicated there were differences among groups. Parametric data from multiple groups were compared using ANOVA followed by $t$ test with modification by Bonferroni's method. Comparisons between two groups were made by the unpaired $t$ test. Linear regression analysis was employed to examine for correlation between sclerosis index and hemodynamic parameters. The results were deemed statistically significant when the $P$ value was $<0.05$.

\section{Results}

\section{Animal and whole kidney data}

Mean values for body weight, SAP, BUN, and total urinary protein excretion $\left(U_{\text {prot }} V\right)$ measured immediately before PAN or saline injection and at subsequent pertinent time intervals in groups I, II, and III, are shown in Table I. Also shown are values for MAP, total GFR and whole kidney sclerosis index assessed at the time of sacrifice. Body weight measured at 0

Table I. PAN, Control and PAN + CEI Rats (Groups I, II, and III) Whole-Animal Data

\begin{tabular}{|c|c|c|c|c|c|c|c|c|c|c|c|c|c|c|c|}
\hline & \multicolumn{3}{|c|}{ Body weight } & & SAP* & & \multicolumn{3}{|c|}{ BUN } & \multicolumn{3}{|c|}{$U_{\text {prou }} V$} & MAP & GFR & $\begin{array}{c}\text { Sclerosis } \\
\text { index }\end{array}$ \\
\hline & \multicolumn{3}{|c|}{$g$} & \multicolumn{3}{|c|}{$m m H g$} & \multicolumn{3}{|c|}{$m g / d l$} & \multicolumn{3}{|c|}{$m g / 24 h$} & $\mathrm{mmHg}$ & $\mathrm{ml} / \mathrm{min}$ & \\
\hline wk & 0 & 4 & 8 & 0 & 4 & 8 & 0 & 4 & 8 & 0 & 4 & 8 & & At sacrif & \\
\hline $\begin{array}{l}\text { Group I (PAN) } \\
\quad(n=6)^{\ddagger}\end{array}$ & $\begin{array}{r}224 \\
\pm 9\end{array}$ & $\begin{array}{r}237 \\
\pm 12\end{array}$ & $\begin{array}{r}213 \\
\pm 17\end{array}$ & $\begin{array}{r}122 \\
\pm 4\end{array}$ & $\begin{array}{r}125 \\
\pm 4\end{array}$ & $\begin{array}{r}122 \\
\pm 3\end{array}$ & $\begin{array}{r}26 \\
\pm 2\end{array}$ & $\begin{array}{r}29 \\
\pm 2\end{array}$ & $\begin{array}{r}41 \\
\pm 3\end{array}$ & $\begin{array}{r}7 \\
\pm 1\end{array}$ & $\begin{array}{r}313 \\
\pm 40\end{array}$ & $\begin{array}{r}348 \\
\pm 84\end{array}$ & $\begin{array}{r}105 \\
\pm 2\end{array}$ & $\begin{array}{r}0.57 \\
\pm 0.07\end{array}$ & $\begin{array}{r}0.80 \\
\pm 0.06\end{array}$ \\
\hline $\begin{array}{l}\text { Group II } \\
\text { (control) } \\
(n=7)\end{array}$ & $\begin{array}{r}220 \\
\pm 9\end{array}$ & $\begin{array}{r}260 \\
\pm 6\end{array}$ & $\begin{array}{r}286 \\
\pm 9\end{array}$ & $\begin{array}{r}118 \\
\pm 2\end{array}$ & $\begin{array}{r}118 \\
\pm 2\end{array}$ & $\begin{array}{r}122 \\
\pm 2\end{array}$ & $\begin{array}{r}25 \\
\pm 1\end{array}$ & $\begin{array}{r}25 \\
\pm 3\end{array}$ & $\begin{array}{r}26 \\
\pm 1\end{array}$ & $\begin{array}{r}11 \\
\pm 2\end{array}$ & $\begin{array}{l}23 \\
\pm 2\end{array}$ & $\begin{array}{r}18 \\
\pm 4\end{array}$ & $\begin{array}{r}108 \\
\pm 2\end{array}$ & $\begin{array}{r}1.46 \\
\pm 0.08\end{array}$ & $\begin{array}{r}0.05 \\
\pm 0.02\end{array}$ \\
\hline $\begin{array}{l}\text { Group III } \\
\text { (PAN + CEI) } \\
(n=5)^{\ddagger}\end{array}$ & $\begin{array}{r}232 \\
\pm 6\end{array}$ & $\begin{array}{r}207 \\
\pm 17\end{array}$ & $\begin{array}{r}234 \\
\pm 17\end{array}$ & $\begin{array}{r}94 \\
\pm 3\end{array}$ & $\begin{array}{l}95 \\
\pm 2\end{array}$ & $\begin{array}{r}100 \\
\pm 4\end{array}$ & $\begin{array}{r}26 \\
\pm 1\end{array}$ & $\begin{array}{r}31 \\
\pm 1\end{array}$ & $\begin{array}{r}32 \\
\pm 3\end{array}$ & $\begin{array}{r}10 \\
\pm 2\end{array}$ & $\begin{array}{r}320 \\
\pm 146\end{array}$ & $\begin{array}{r}271 \\
\pm 131\end{array}$ & $\begin{array}{r}87 \\
\pm 4\end{array}$ & $\begin{array}{r}0.94 \\
\pm 0.11\end{array}$ & $\begin{array}{r}0.53 \\
\pm 0.08\end{array}$ \\
\hline $\begin{array}{l}P \text { value }^{\S} \\
\text { (I vs. II) }\end{array}$ & NS & NS & $<0.005$ & NS & NS & NS & NS & NS & $<0.005$ & NS & $<0.001$ & $<0.005$ & NS & $<0.001$ & $<0.001$ \\
\hline $\begin{array}{l}P \text { value }^{\S} \\
\quad \text { (I vs. III) }\end{array}$ & NS & NS & NS & $<0.001$ & $<0.001$ & $<0.001$ & NS & NS & NS & NS & NS & NS & $<0.001$ & $<0.01$ & $<0.01$ \\
\hline $\begin{array}{l}P \text { value }^{\S} \\
\text { (II vs. III) }\end{array}$ & NS & NS & NS & $<0.001$ & $<0.001$ & $<0.001$ & NS & NS & NS & NS & NS & NS & $<0.001$ & $<0.005$ & $<0.001$ \\
\hline
\end{tabular}

Values are expressed as mean \pm 1 SE. * The listed values of SAP were obtained from awake animals one day before each micropuncture experiment. The values were essentially identical to those of the anesthetized animals just before the micropuncture experiment. ${ }^{\ddagger}$ Three rats were added for measurements of MAP, GFR, and sclerosis index. ${ }^{\S}$ ANOVA followed by $t$ test with Bonferroni's modification was done. Nonparametric data (sclerosis index) were analyzed by Mann-Whitney $U$ test. 
Table II. ADM and Control (Groups IV and V) Whole-Animal Data

\begin{tabular}{|c|c|c|c|c|c|c|c|c|c|c|c|c|c|c|c|}
\hline \multirow[b]{3}{*}{ wk } & \multicolumn{3}{|c|}{ Body weight } & \multicolumn{3}{|c|}{ SAP* } & \multicolumn{3}{|c|}{ BUN } & \multicolumn{2}{|c|}{$U_{\text {prot }} Y$} & \multirow{2}{*}{\multicolumn{2}{|c|}{$\begin{array}{c}\text { MAP } \\
m m H g\end{array}$}} & \multirow{2}{*}{$\frac{\mathrm{GFR}}{\mathrm{ml} / \mathrm{min}}$} & \multirow[t]{2}{*}{$\begin{array}{c}\text { Sclerosis } \\
\text { index }\end{array}$} \\
\hline & & $g$ & & & $m m H g$ & & & $m g / d l$ & & & $124 h$ & & & & \\
\hline & 0 & $15-19$ & $27-31$ & 0 & $15-19$ & $27-31$ & 0 & $15-19$ & $27-31$ & 0 & $15-19$ & $27-31$ & & At sacrific & \\
\hline $\begin{array}{c}\text { Group IV } \\
\left(\begin{array}{c}\text { ADM }) \\
(n=7)\end{array}\right.\end{array}$ & $\begin{array}{r}215 \\
\pm 9\end{array}$ & $\begin{array}{r}300 \\
\pm 11\end{array}$ & $\begin{array}{r}314 \\
\pm 18\end{array}$ & $\begin{array}{r}118 \\
\pm 3\end{array}$ & $\begin{array}{r}127 \\
\pm 7\end{array}$ & $\begin{array}{r}137 \\
\pm 4\end{array}$ & $\begin{array}{r}18 \\
\pm 1\end{array}$ & $\begin{array}{r}23 \\
\pm 4\end{array}$ & $\begin{array}{r}40 \\
\pm 7\end{array}$ & $\begin{array}{r}10 \\
\pm 2\end{array}$ & $\begin{array}{r}290 \\
\pm 47\end{array}$ & $\begin{array}{r}246 \\
\pm 48\end{array}$ & $\begin{array}{r}117 \\
\pm 4\end{array}$ & $\begin{array}{r}0.41 \\
\pm 0.10\end{array}$ & $\begin{array}{r}1.11 \\
\pm 0.20\end{array}$ \\
\hline $\begin{array}{l}\text { Group V } \\
\quad \begin{array}{l}\text { control) } \\
(n=18)^{\ddagger}\end{array}\end{array}$ & - & $\begin{array}{r}332 \\
\pm 14\end{array}$ & $\begin{array}{r}362 \\
\pm 14\end{array}$ & - & $\begin{array}{r}120 \\
\pm 4\end{array}$ & $\begin{array}{r}119 \\
\pm 5\end{array}$ & - & $\begin{array}{r}20 \\
\pm 1\end{array}$ & $\begin{array}{r}23 \\
\pm 1\end{array}$ & - & - & $\begin{array}{r}8 \\
\pm 2\end{array}$ & $\begin{array}{r}106 \\
\pm 3\end{array}$ & $\begin{array}{r}0.99 \\
\pm 0.08\end{array}$ & $\begin{array}{r}0.02 \\
\pm 0.01\end{array}$ \\
\hline$P$ value ${ }^{8}$ & - & NS & $<0.05$ & - & NS & $<0.05$ & - & NS & $<0.05$ & - & - & $<0.005$ & $<0.05$ & $<0.001$ & $<0.001$ \\
\hline
\end{tabular}

Values are expressed as mean $\pm 1 \mathrm{SE}$. * The listed values of SAP were obtained from awake animals $1 \mathrm{~d}$ before each micropuncture experiment. The values were essentially identical to those of the anesthetized animals just before the micropuncture experiment. ${ }^{\ddagger}$ Six animals were studied for each time period of $7 \mathrm{wk}, 15-19 \mathrm{wk}$, or $27-31 \mathrm{wk}$. ${ }^{8} t$ tests were performed between group IV vs. group V; NS: $P>0.05$. Nonparametric data (sclerosis index) were analyzed by ANOVA with Kruskall-Wallis test followed by Mann-Whitney U test.

week of group I, II, and III animals was essentially identical. Body weight of group II control rats increased with time, with a $30 \%$ average weight gain by $8 \mathrm{wk}$. In contrast, body weight of group I PAN-treated rats decreased on an average of $5 \%$ by 8 wk. Body weight of group III PAN + CEI-treated rats decreased during the first 4 wk but increased subsequently, and by 8 wk had returned to baseline. While SAP remained essentially unchanged and comparable throughout the study in groups I and II rats, SAP in group III was some $20-30 \mathrm{mmHg}$ lower than those of group I and II during the 0-8 wk period. BUN values measured in group II control rats remained essentially constant throughout the period $(25-26 \mathrm{mg} / \mathrm{dl})$. In group I PAN-treated rats, BUN increased gradually and reached an average value of $41 \mathrm{mg} / \mathrm{dl}$ at $8 \mathrm{wk}$, a value significantly higher than that of group II. In group III PAN + CEItreated rats, BUN increased to $32 \mathrm{mg} / \mathrm{dl}$ at $8 \mathrm{wk}$, a value numerically lower than that of group $I$, although this difference did not reach statistical significance. $U_{\text {prot }} V$ in groups I and III increased by $4 \mathrm{wk}$ to comparable levels (on average 313 and $320 \mathrm{mg} / \mathrm{d}$, respectively). Thereafter, $U_{\text {prot }} V$ further increased, on average, to $348 \mathrm{mg} / \mathrm{d}$ at $8 \mathrm{wk}$ in group I, whereas $U_{\text {prot }} V$ decreased on average to $271 \mathrm{mg} / \mathrm{d}$ in group III. Finally, whole kidney GFR in group I averaged $0.57 \mathrm{ml} / \mathrm{min}$ at the completion of the study, a value significantly lower than that of group II $(1.46 \mathrm{ml} / \mathrm{min})$ and group III $(0.94 \mathrm{ml} / \mathrm{min})$. Although not apparent in Table I, within group I there was a strong inverse correlation between total GFR value and whole kidney sclerosis index determined in each rat $(P<0.05)$.

Mean values for body weight, SAP, BUN, and $U_{\text {prot }} V$ measured on the day of initial $\mathrm{ADM}$ injection and at subsequent pertinent time intervals in groups IV and $\mathrm{V}$ are shown in Table II. Also shown are values for MAP, total GFR and whole kidney sclerosis index assessed at the time of sacrifice. Average body weight of group IV ADM-treated rats was lower than that of group V control rats at both 15-19 wk and 27-31 wk. Values of SAP and BUN of group IV increased gradually and became significantly higher than those of group $\mathrm{V}$ by 27-31 wk. In group IV ADM-treated rats values for $U_{\text {prot }} V$ increased markedly and averaged $290 \mathrm{mg} / \mathrm{d}$ at $15-19$ wk and $246 \mathrm{mg} / \mathrm{d}$ at 27-31 wk, whereas $U_{\text {prot }} V$ values averaged $8 \mathrm{mg} / \mathrm{d}$ at $27-31$ wk in group $\mathrm{V}$ control rats. Finally, whole kidney GFR in group IV at the completion of the study averaged $0.41 \mathrm{ml} / \mathrm{min}$, $<50 \%$ of group V control $(0.99 \mathrm{ml} / \mathrm{min})$, a statistically significant difference. Although not shown in Table II, within group IV there was a strong inverse correlation between total GFR and whole kidney sclerosis index determined in each rat $(P$ $<0.01$ ).

\section{Micropuncture measurements}

The time course of SNGFR values of group I PAN-treated rats is shown in Figs. $2 A$ and $B .^{2}$ In these figures the time course of SNGFR in group II control rats is given by an open band $(31.4 \pm 3.5$ [mean $\pm \mathrm{SE}] \mathrm{nl} / \mathrm{min}$ at $0 \mathrm{wk}, 34.5 \pm 2.1$ at $4 \mathrm{wk}$, $42.1 \pm 2.3$ at $8 \mathrm{wk}$ ). As shown, values for SNGFR decreased progressively in almost all nephrons (Fig. $2 B$ ) and kidneys (Fig. $2 A$ ) studied in group I. Initial average values of SNGFR in each group I rat ranged $21.1-33.8 \mathrm{nl} / \mathrm{min}$, declining to $6.2-18.8 \mathrm{nl} / \mathrm{min}$ by the time of sacrifice. As shown in Fig. $2 B$, which presents data from a representative PAN kidney, several nephrons displayed an increase in SNGFR before a decline at the end of the study. However, no nephrons showed an increase of SNGFR above the levels measured in group II control rats. As shown by the increasing standard errors depicted by the vertical bars in Fig. $2 A$, internephron variability of SNGFR tended to become more marked with time in group I PAN-treated animals (standard error 1.0-2.8 at 0 wk; $1.2-5.7$ at $8 \mathrm{wk}$ ).

Data from sequential $P_{\mathrm{GC}}$ assessment in group I PANtreated rats is shown in Fig. $2 C$ and $D$ in a fashion similar to that of Fig. $2 A$ and $B$. $P_{\mathrm{GC}}$ values in group I remained constant or tended to decline in almost all glomeruli (Fig. $2 \mathrm{D}$ ) and kidneys (Fig. $2 C$ ). Average baseline values of $P_{\mathrm{GC}}$ ranged 49-60 $\mathrm{mmHg}$ and average values of $P_{\mathrm{GC}}$ at the completion of the study ranged $40-50 \mathrm{mmHg}$. As shown in Fig. $2 D, P_{\mathrm{GC}}$ increased in some nephrons. However, again, there was no nephron which showed an increase of $P_{G C}$ above the control levels $(53.0 \pm 2.0 \mathrm{mmHg}$ at $0 \mathrm{wk}, 55.0 \pm 1.7$ at $4 \mathrm{wk}, 53.0 \pm 1.2$ at $8 \mathrm{wk})$. On the other hand, values for $P_{\mathrm{BS}}$ uniformly remained

2. The baseline SNGFR is somewhat lower than previously described, which may be due to the effects of anesthesia with Nembutal (a shortacting barbiturate) without tracheal intubation. 

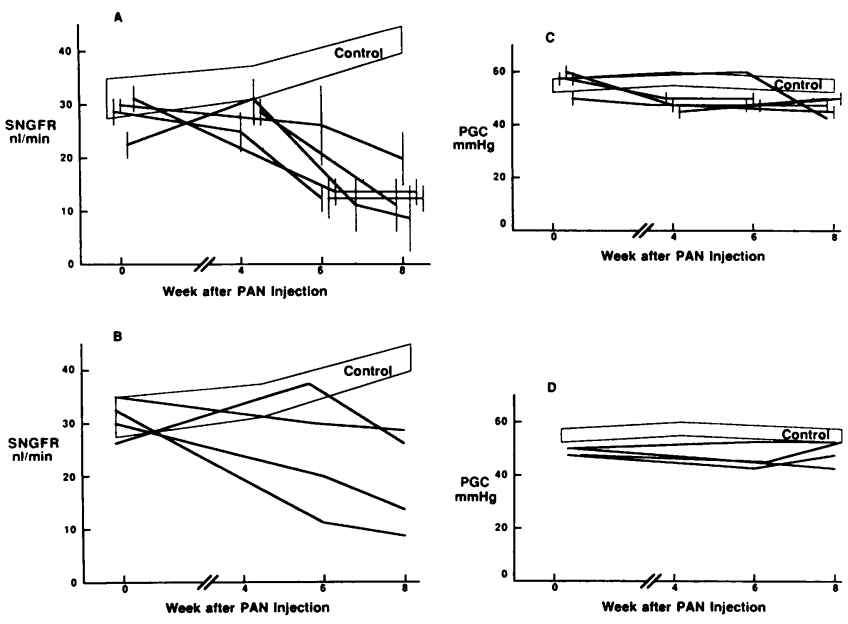

Figure 2. Time course of SNGFR in group I PAN-treated rats $(A, B)$. In $A$, each solid line denotes the time course of average SNGFR values obtained from each rat. Vertical bars indicate $\pm 1 \mathrm{SE}$. The time course of SNGFR in nephrons of group II nephrectomized control rats is given by an open band (mean $\pm 1 \mathrm{SE}$ ). In B, each line gives the time course of SNGFR assessed in each nephron from one representative kidney. Time course of $P_{\mathrm{GC}}$ in group I PAN-treated rats is given in $C$ and $D$ in a fashion similar to that of $A$ and $B$, respectively. At 4 and $8 \mathrm{wk}$, there is a statistically significant difference between the average SNGFR $(P<0.05$ and $P<0.001$, respectively) and $P_{\mathrm{GC}}(P<0.05$ and $P<0.025$, respectively) in control and PANtreated rats.

constant throughout the study $(15 \pm 1 \mathrm{mmHg})$, and the values were essentially the same as those in group II control rats $(14 \pm 1 \mathrm{mmHg})$. Thus, the time course of glomerular transcapillary hydraulic pressure difference exhibited a pattern identical to that of $P_{\mathrm{GC}}$ in both groups I and II.

When PAN-treated rats were given CEI (group III), average SNGFR values tended to show slightly higher levels immediately before sacrifice compared to animals just given PAN (group I) (18.3 nl/min vs. 11.5, respectively). As shown in Fig. $3 A$, with CEI treatment (group III), average $P_{\mathrm{GC}}$ (thick line) remained at control levels (open band) throughout the 8-wk period $(51.6 \pm 1.5 \mathrm{mmHg}$ at $0 \mathrm{wk}, 53.8 \pm 0.8$ at $4 \mathrm{wk}, 51.9 \pm 1.5$ at $8 \mathrm{wk}$ ), while average levels of $P_{\mathrm{GC}}$ in group I (thin line) tended to remain at levels slightly below the control levels (53.5 $\pm 1.3 \mathrm{mmHg}$ at $0 \mathrm{wk}, 48.0 \pm 1.2$ at $4 \mathrm{wk}, 47.5 \pm 1.6$ at $8 \mathrm{wk}$ ).

Data from serial SNGFR and $P_{G C}$ assessment in group IV ADM-treated rats is shown in Fig. $4 A-D$. In these figures, the time course of SNGFR and $P_{\mathrm{GC}}$ in group $\mathrm{V}$ control rats is given by an open band $(25.0 \pm 1.2 \mathrm{nl} / \mathrm{min}$ at $7 \mathrm{wk}, 24.8 \pm 1.5$ at $19 \mathrm{wk}, 24.1 \pm 1.7$ at $31 \mathrm{wk})$. In group IV there was a substantial decline in average SNGFR values in four animals while two animals showed essentially no change in average SNGFR values (Fig. $4 A$ ). As shown in Fig. $4 B$, within each kidney there was a marked variability in SNGFR values among nephrons, with many nephrons showing a decrease in SNGFR while in some an increase in SNGFR was demonstrated. In contrast to group I PAN-treated rats, some hyperfiltrating glomeruli (SNGFR, up to $41.6 \mathrm{nl} / \mathrm{min}$ ) were found by $15 \mathrm{wk}$ after the first ADM injection.

Similar to PAN-treated group I, $P_{\mathrm{GC}}$ levels in ADM-treated group IV remained constant or tended to decline in almost all glomeruli (Fig. $4 \mathrm{D}$ ) and kidneys (Fig. $4 \mathrm{C}$ ). Average baseline
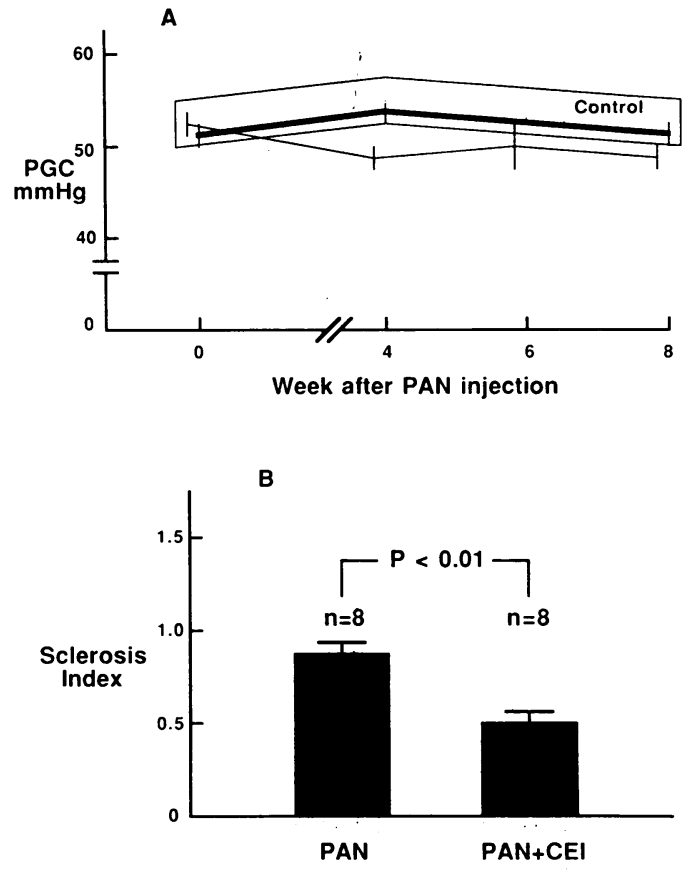

Figure 3. (A) Time course of $P_{\mathrm{GC}}$ in group III PAN-treated rats given captopril is presented by the thick line. For comparison, the time courses of $P_{\mathrm{GC}}$ in PAN rats without captopril treatment (group I) (thin line) and group II control rats (open band) are also given. In this diagram the length of the vertical bars on the solid lines and the height of the open bar indicate \pm 1 SE. (B) A comparison of the sclerosis index between group I PAN-treated rats and group III PANtreated rats given captopril (CEI) orally, assessed at the completion of study.

levels of $P_{\mathrm{GC}}$ ranged 46-50 $\mathrm{mmHg}$ and average values of $P_{\mathrm{GC}}$ at the completion of study ranged $39-47 \mathrm{mmHg}$. There were no nephrons with $P_{\mathrm{GC}}$ values above the control levels $(46.8 \pm 1.6$, $45.7 \pm 0.4,45.6 \pm 0.8 \mathrm{mmHg}$ at $7,19,31 \mathrm{wk}$, respectively) with the exception of one glomerulus $(55 \mathrm{mmHg})$. Values of $P_{\mathrm{BS}}$ were uniform and remained essentially unchanged throughout the study $(12 \pm 0.3 \mathrm{mmHg})$ in group IV animals, and the values were essentially the same as in group $\mathrm{V}$ control rats $(13 \pm 0.3$ $\mathrm{mmHg})$.

\section{Histological studies}

In ADM-treated group IV rats there was segmental hyalinosis and sclerosis in many glomeruli. Many obsolescent glomeruli were also present. Mesangial proliferation was closely associated with the segmental sclerosis. The segmental distribution was apparent by analyzing serial sections of a given glomerulus. Some sections revealed only minimal changes with synechiae or normal light microscopic morphology. In other serial sections from the same glomerulus, severe segmental sclerosis could be detected. In contrast, the PAN lesion in our model was characterized by somewhat less severe changes. Synechiae were prominent as were cyst or bleb formation and were less segmentally distributed than the ADM sclerosis. In glomeruli where hyalinosis or sclerosis was present, it tended to involve a lesser portion of the glomerulus than in the ADM sclerotic glomeruli. Thus, in PAN-treated group I rats the mean whole kidney sclerosis index was 0.80 versus 1.11 in ADM-treated group IV rats. As shown in Fig. $3 B$, with CEI treatment in the PAN rats (group III), a substantial difference was noted. The 


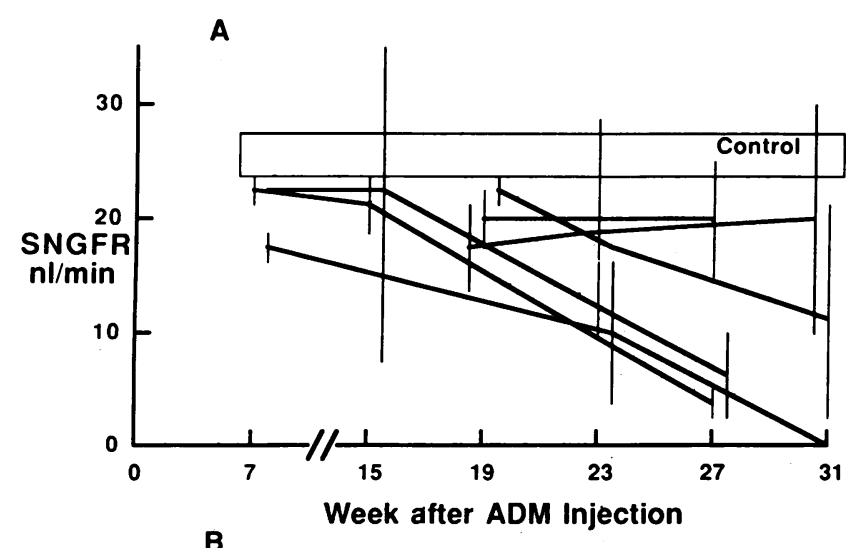

B

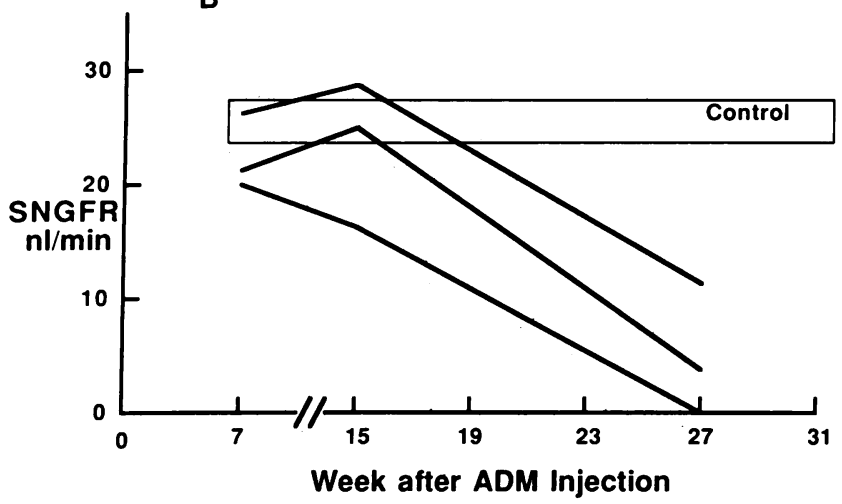

Figure 4. Time course of SNGFR in group IV ADM-treated rats $(A$, $B)$. In A, each solid line denotes the time course of average SNGFR values obtained from each rat. Vertical bars indicate \pm 1 SE. SNGFR in nephrons of group $\mathrm{V}$ nonnephrectomized control rats is given by an open band (mean $\pm 1 \mathrm{SE}$ ). In B, each line gives the time course of

sclerosis index of group III CEI-treated rats (average: 0.53 ) was significantly lower than that of group I CEI-untreated rats (0.80) $(P<0.01)$. Although sclerosis was quantitatively less with CEI treatment, the nature of the structural changes remained the same. Thus, group III PAN + CEI treated rats also had a glomerular lesion characterized by cyst formation and a more diffuse and less segmental lesion than that seen in ADM-treated group IV glomeruli. Control nephrons of group II and group V showed virtually no sclerosis (average sclerosis index: 0.05 and 0.02 , respectively) and no cyst formation was present.

Histological changes at single nephron levels were compared to the time course patterns of SNGFR and $P_{\mathrm{GC}}$, and overall changes in SNGFR and $P_{\mathrm{GC}}$. In group I PAN-treated rats, when maximum values of SNGFR in early stage (0-4 wk after the first PAN injection) were plotted against the sclerosis index for each glomerulus, no correlation was seen $(r=0.03$, NS). The sclerosis index also did not correlate with baseline SNGFR ( $r=0.12$, NS). As shown in Fig. $5 A$, however, there was a strong inverse correlation between sclerosis index and SNGFR measured at the completion of the study $(r=0.56, P$ $<0.01)$. Although not shown, $P_{\mathrm{GC}}$ values, either maximum in the early stage ( $r=0.47, \mathrm{NS})$, average ( $r=0.46, \mathrm{NS})$, or values assessed immediately before sacrifice ( $r=0.02$, NS), showed no correlation with sclerosis index in group I PAN-rats. In group IV ADM-treated rats, there was a significant inverse correlation between maximum SNGFR in the early stage (7-23 wk after the first ADM injection) and sclerosis index ( $r$
C
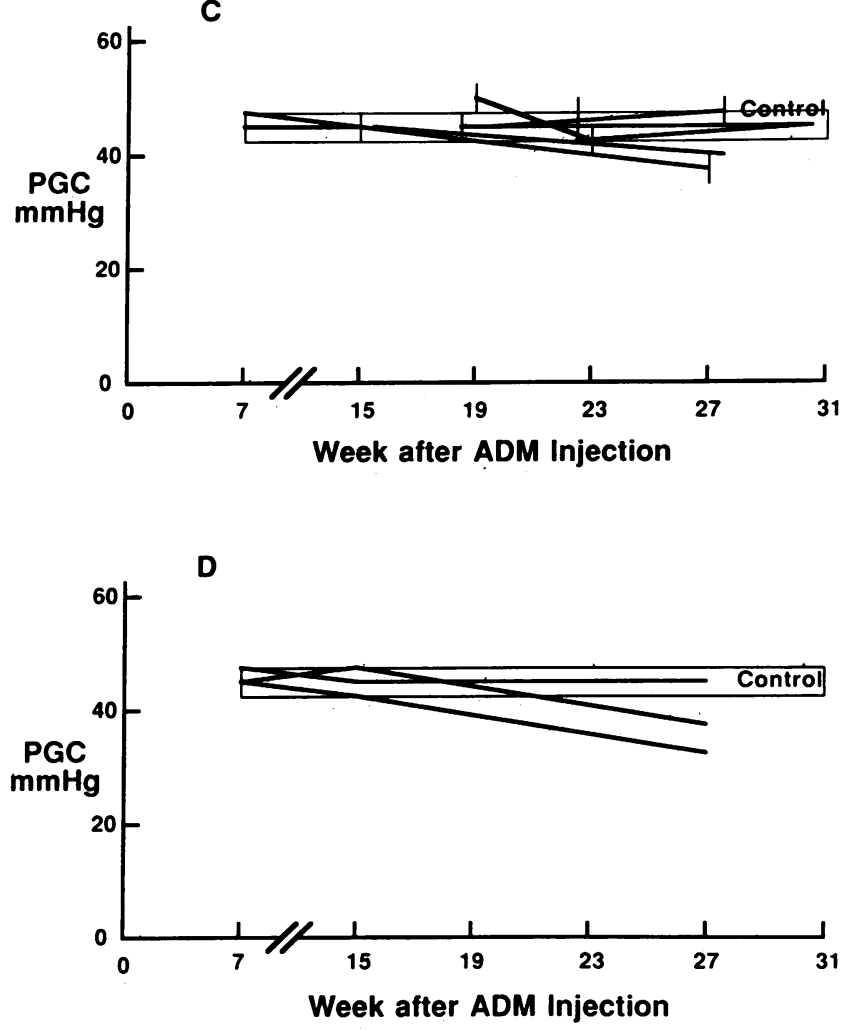

SNGFR assessed in each nephron from one representative kidney. The time course of $P_{\mathrm{GC}}$ in group IV ADM-treated rats is given in C and $D$ in a fashion similar to that of $A$ and $B$, respectively. At 27-31 wk, there is a statistically significant difference $(P<0.01)$ between the average SNGFR in control and ADM-treated rats.

$=0.64, P<0.05$ ). Thus, some nephrons that attained higher SNGFR, showed the least degree of subsequent sclerosis. Also, as shown in Fig. $5 \mathrm{~B}$, there was a strong inverse correlation between sclerosis index and SNGFR measured at the completion of the study in group IV rats $(r=0.66, P<0.01)$. Although not shown, $P_{\mathrm{GC}}$ values, either maximum in the early stage $(r=0.33, \mathrm{NS})$ or values assessed immediately before sacrifice $(r=0.38, \mathrm{NS})$, showed no correlation with sclerosis index.

\section{Discussion}

The serial micropuncture measurements performed over 8 and 31 wk in PAN- and ADM-treated rats, respectively, revealed that virtually none of the glomeruli in which an appreciable degree of sclerosis developed by the time of sacrifice, had stages of hyperfiltration or abnormally high glomerular capillary hydraulic pressure earlier. In fact, in most nephrons of PAN and ADM rats the glomerular capillary pressure remained at levels slightly below control levels throughout the entire study period and the single nephron filtration rate fell progressively, a trend still continuing at the time of sacrifice. An exception was seen in a small population of nephrons in ADM-treated rats: toward the end of the study, the filtration rate was increased in some nephrons. These nephrons, however, were found to have minimal glomerular structural abnormalities. It is conceivable that more severe glomerular sclerosis 

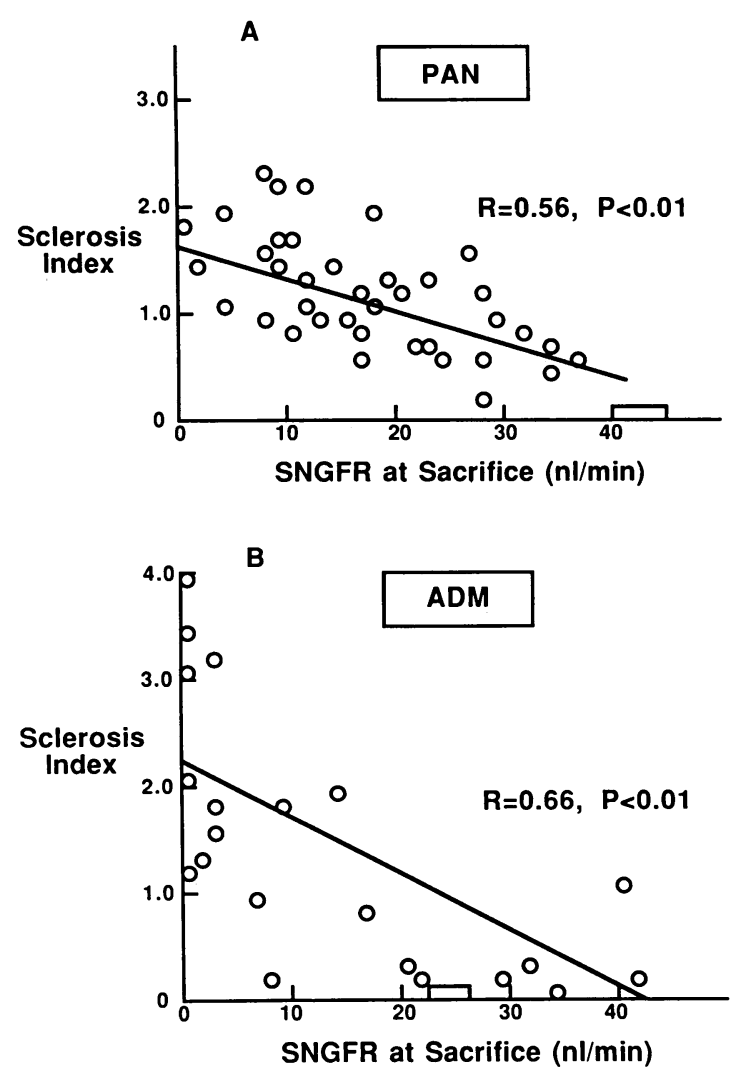

Figure 5. Relationship between sclerosis index vs. the level of SNGFR assessed at the time of sacrifice in each nephron of group I PAN-treated rats $(A)$ and group IV ADM-treated rats $(B)$. The open rectangular zone at the bottom of each panel represents the data obtained in control rats.

would have developed in these hyperfiltering glomeruli, had the duration of observation been longer. However, the supernormal level of SNGFR in these glomeruli was not accompanied by high glomerular pressure at the time of our measurements. At the end of the study, an inverse correlation was seen in both PAN and ADM rats between SNGFR values and the degree of glomerular sclerosis of the same nephrons. Thus, the nephrons with the most severe glomerular structural abnormalities were characterized by having the lowest filtration rate. A similar trend has been observed recently in sclerotic remnant glomeruli following subtotal renal ablation (20).

Because of the tremendous internephron heterogeneity in the later stages of these two models, and since it is technically impossible to sample plasma from the efferent arteriole of the same glomerulus in which SNGFR and $P_{\mathrm{GC}}$ were measured, we could not evaluate all of the determinants for the decreased SNGFR. In the sclerosed glomerulus, the capillaries are collapsed and it is therefore plausible to speculate that capillary surface area, hence $K_{f}$, is decreased. Also, $Q_{\mathrm{A}}$ may decrease due to the sclerosis constricting the hilar area and the afferent arteriole. In addition, reduced $P_{\mathrm{GC}}$, which we sometimes observed in the later stage of our models, may contribute to the decreased SNGFR. Thus, reduced $K_{\mathrm{f}}, Q_{\mathrm{A}}$ and $P_{\mathrm{GC}}$ may all contribute to the decreased SNGFR. In any case, the present study demonstrated that glomerular hyperfunction does not exist prior to, and hence is not a requirement for, the development of glomerular sclerosis in the animal models of PAN and
ADM. While these observations clearly speak against the theory derived from other experimental models, such as subtotal renal ablation and diabetic nephropathy $(18,19)$ that glomerular hyperfiltration and/or hypertension is an obligatory common pathophysiologic pathway (25), they bear no insight as to whether the glomerular hyperfunction which exists in other models indeed exerts an injurious effect on the glomerular architecture.

Since marked functional heterogenetity appears to exist in many forms of human chronic renal diseases, it is impossible to speculate on single nephron hyperfiltration from the evaluation of total kidney GFR. The animal model of subtotal renal ablation has been considered to represent an advanced stage of human chronic renal disease, primarily on the basis of their histological similarity. Glomerular hyperfiltration and hypertension have been demonstrated in the early stage of this model with subsequent glomerular sclerosis (18). In addition, certain experimental maneuvers have been shown to modify the magnitude of these early functional changes and the degree of later structural damage (25). Although the late stage of many experimental models histologically closely resembles the human end stage kidney, it should be noted that the initial damage in the animal model of subtotal renal ablation is extremely focal and seems to be comparable clinically to rather unusual forms of renal injury. In this regard, ADM or PAN models, where the initial insult is directed against all nephrons, appear to more closely simulate many forms of human chronic renal diseases. Our results may therefore be taken to indicate that in those human diseases where all glomeruli are initially exposed to a pathogenic insult, glomerular hyperfunction is not required for the development of glomerular sclerosis.

Having observed the serial functional changes in PAN and ADM models and demonstrated a progression of glomerular sclerosis independent of glomerular pressure and filtration, we wished to test at least one intervention that in the past has been shown to attenuate the development of glomerular sclerosis. We therefore examined if CEI exerts a protective effect on the PAN-treated rats, as found in the models of subtotal ablation of renal mass (26) and streptozotocin-induced diabetes mellitus (27). As described in Results, whereas CEI was essentially without effect on glomerular capillary pressure, it attenuated significantly and substantially the development of glomerular sclerosis in PAN rats. In a recent study of a chronic PAN model (28), ACE inhibition was not found to have a detectable protective effect on glomerular structure. Although glomerular sclerosis was quantitated by a different method, in their study only $12-13 \%$ of glomeruli had hyalinosis or sclerosis, whereas in our model the majority of glomeruli were affected. Thus, it appears that the protective effect of CEI in PAN-induced glomerular sclerosis is only demonstrable experimentally when there is more than mild glomerular sclerosis. In our study CEI did not completely ameliorate glomerular sclerosis, although it is possible that higher doses of captopril might have resulted in an even greater decrease in sclerosis. Our observations indicate that PAN-induced glomerular sclerosis was derived at least in part by CEI-sensitive mechanism(s) which operate independently of glomerular capillary pressure. Thus, in this PAN model, CEI appears to partially protect the kidney from glomerular sclerosis, and the protective effect does not appear to be channeled through a decrease in glomerular capillary pressure. Since CEI had no effect on glomerular capillary pressure 
in the present study, our results do not elucidate whether the association between reduction in glomerular pressure and attenuation of glomerular sclerosis following CEI seen in other experimental models is indeed a causal one $(26,27)$.

How, then, did CEI attenuate the development of sclerosis in PAN-treated rats? In vivo and in vitro studies conducted in humans and animals during the past several years indicate that CEI exerts its action through both angiotensin-dependent and independent pathways (29). Moreover, a variety of cell types in addition to smooth muscle cells, including macrophages, brain cells and $\mathrm{T}$ lymphocytes, have been found to have angiotensin I converting enzyme (ACE) activity (30-37). In addition, a wide variety of biological actions of CEI (and ACE) has been reported $(32,37-40)$. Thus, it is difficult to propose a simple scheme to explain the role of ACE and CEI on the glomerular structure in the PAN-treated rats. In a study using chronic PAN-treated rats, infusion of a competitive antagonist of angiotensin II was shown to markedly attenuate the accumulation of macromolecules in the mesangium (41). In chronically treated PAN and subtotal nephrectomy models, the macromolecule accumulation occurs in the mesangium before sclerosis develops (42-44). Thus, CEI may be exerting its protective effect in the current study by preventing mesangial macromolecular deposition. Alternatively, since angiotensin II is known to directly stimulate proliferation of some angiotensin iI receptor-bearing cells (45-47), the protective effect of CEI on the glomerular structure in PAN rats may be channeled through inhibition of a hypertrophic or mitogenic angiotensin II effect on glomerular mesangial cells (48). Further possible mechanisms may relate to angiotensin II independent actions of CEI. CEI has been shown to enhance the cyclooxygenase pathway of arachidonic acid metabolism in blood vessels and isolated glomeruli $(38,49-51)$. Products of the cyclooxygenase pathway, in turn, directly or indirectly attenuate cell proliferation $(38,52-58)$. In our recent preliminary study a strong correlation was found between glomerular hypertrophy and sclerosis at the single nephron level in a model of subtotal nephrectomy (59). Therefore, it is conceivable that the protective effect of CEI on glomerular structure observed in the present study may be mediated by enhanced production of arachidonic acid metabolites that attenuate glomerular growth. Consistent with this concept is our observation of significant attenuation of glomerular maturational growth when CEI was given to young rats, although there was no effect on $P_{\mathrm{GC}}(60)$. Moreover, prostaglandins of both exogenous and endogenous origin were shown to inhibit glomerular cell proliferation and mesangial matrix formation in vitro (61).

In summary, the studies presented in this article show that in the PAN and ADM models sclerosis occurs without preceding glomerular hypertension or hyperfiltration. Additionally, CEI treatment diminished sclerosis substantially without affecting the glomerular capillary pressure, thus further supporting our conclusion that nonhemodynamic factors are instrumental in the production of glomerular sclerosis in these two experimental models.

\section{Acknowledgments}

The authors are grateful to Dr. John R. Hoyer and Dr. Hiroshi Shiraga for valuable suggestions during our studies and preparation of this manuscript.
These studies were supported by National Institute of Health grant DK-37868. Dr. Ichikawa is a recipient of Established Investigatorship Award from the American Heart Association.

\section{References}

1. Frenk, S., I. Antonowicz, J. M. Craig, and J. Metcoff. 1955. Experimental nephrotic syndrome induced in rats by aminonucleoside. Renal lesions and body electrolyte composition. Proc. Soc. Exp. Biol. Med. 89:424-427.

2. Vernier, R. L., B. W. Papernaster, and R. A. Good. 1959. Aminonucleoside nephrosis. I. Electron microscopic study of the renal lesion in rats. J. Exp. Med. 109:115-126.

3. Farquhar, M. G., and G. E. Palade. 1961. Glomerular permeability. II. Ferritin transfer across the glomerular capillary wall in nephrotic rats. J. Exp. Med. 114:699-716.

4. Arakawa, M. 1970. A scanning electron microscopy of the glomerulus of normal and nephrotic rats. Lab. Invest. 23:489-496.

5. Venkatachalam, M. A., R. S. Cotran, and M. J. Karnovsky. 1970. An ultrastructural study of glomerular permeability in aminonucleoside nephrosis using catalase as a tracer protein. J. Exp. Med. 132:1168-1180.

6. Oken, D. E., and W. Flamenbaum. 1971. Micropuncture studies of proximal tubule albumin concentrations in normal and nephrotic rats. J. Clin. Invest. 50:1498-1505.

7. Mauer, S. M., A. J. Fish, E. B. Blau, and A. F. Michael. 1972. The glomerular mesangium. I. Kinetic studies of macromolecular uptake in normal and nephrotic rats. J. Clin. Invest. 51:1092-1101.

8. Ryan, G. B., and M. J. Karnovsky. 1975. An ultrastructural study of the mechanisms of proteinuria in aminonucleoside nephrosis. Kidney Int. 8:219-232.

9. Hoyer, J. R., S. M. Mauer, and A. F. Michael. 1975. Unilateral renal disease in the rat. I. Clinical, morphologic, and glomerular mesangial functional features of the experimental model produced by renal perfusion with aminonucleoside. J. Lab. Clin. Med. 85:756-768.

10. Caulfield, J. P., J. J. Reid, and M. G. Farquhar. 1976. Alterations of the glomerular epithelium in acute aminonucleoside nephrosis. Evidence for formation of occluding junctions and epithelial cell detachment. Lab. Invest. 34:43-59.

11. Kerjaschki, D., A. T. Vernillo, and M. G. Farquhar. 1985. Reduced sialylation of podocalyxin-the major sialoprotein of the rat kidney glomerulus-in aminonucleoside nephrosis. Am. J. Pathol. 118:343-349.

12. Diamond, J. R., and M. J. Karnovsky. 1986. Focal and segmental glomerulosclerosis following a single intravenous dose of puromycin aminonucleoside. Am. J. Pathol. 122:481-487.

13. Glasser, R. J., J. A. Velosa, and A. F. Michael. 1977. Experimental model of focal sclerosis. I. Relationship to protein excretion in aminonucleoside nephrosis. Lab. Invest. 36:519-526.

14. Bertani, T., A. Poggi, R. Pozzoni, F. Delaini, G. Sacchi, Y. Thoua, G. Mecca, G. Remuzzi, and M. B. Donati. 1982. Adriamycininduced nephrotic syndrome in rats: sequence of pathologic events. Lab. Invest. 46:16-23.

15. Weening, J. J., and H. G. Rennke. 1983. Glomerular permeability and polyanion in adriamycin nephrosis in the rat. Kidney Int. 24:152-159.

16. Okuda, S., Y. Oh, H. Tsuruda, K. Onoyama, S. Fujimi, and M. Fujishima. 1986. Adriamycin-induced nephropathy as a model of chronic progressive glomerular disease. Kidney Int. 29:502-510.

17. Ichikawa, I., H. G. Rennke, J. R. Hoyer, K. F. Badr, N. Schor, J. L. Troy, C. P. Lechene, and B. M. Brenner. 1983. Role for intrarenal mechanisms in the impaired salt excretion of experimental nephrotic syndrome. J. Clin. Invest. 71:91-103.

18. Hostetter, T. H., J. L. Olson, H. G. Rennke, M. A. Venkatachalam, and B. M. Brenner. 1981. Hyperfiltration in remnant nephrons: a potentially adverse response to renal ablation. $A m$. J. Physiol. 241:F85-F93.

19. Hostetter, T. H., J. L. Troy, and B. M. Brenner. 1981. Glomer- 
ular hemodynamics in experimental diabetes mellitus. Kidney Int. 19:410-415.

20. Yoshida, Y., A. Fogo, H. Shiraga, A. D. Glick, and I. Ichikawa. 1988. Serial micropuncture analysis of single nephron function in the rat model of subtotal renal ablation. Kidney Int. 33:855-867.

21. Pfeffer, J. M., M. A. Pfeffer, and E. D. Frohlich. 1971. Validity of an indirect tail-cuff method for determining systolic arterial pressure in unanesthetized normotensive and spontaneously hypertensive rats. J. Lab. Clin. Med. 78:957-962.

22. Raij, L., S. Azar, and W. Keane. 1984. Mesangial immune injury, hypertension, and progressive glomerular damage in Dahl rats. Kidney Int. 26:137-143.

23. Führ, J., J. Kaczmarczyk, and C. D. Krüttgen. 1955. Eine einfache colorimetrische Methode zur Inulin Bestimmung für NierenClearanceuntersuchungen bei Stoffwechselgesunden und Diabetikern. Klin. Wochenschr. 33:729-730.

24. Bradford, M. M. 1976. A rapid and sensitive method for the quantitation of microgram quantities of protein utilizing the principle of protein-dye binding. Anal. Biochem. 72:248-254.

25. Brenner, B. M., T. W. Meyer, and T. H. Hostetter. 1982. Dietary protein intake and the progressive nature of kidney disease: The role of hemodynamically mediated glomerular injury in the pathogenesis of progressive glomerular sclerosis in aging, renal ablation, and intrinsic renal disease. N. Engl. J. Med. 307:652-659.

26. Anderson, S., H. G. Rennke, and B. M. Brenner. 1986. Therapeutic advantage of converting enzyme inhibitors in arresting progressive renal disease associated with systemic hypertension in the rat. $J$. Clin. Invest. 77:1993-2000.

27. Zatz, R., B. R. Dunn, T. W. Meyer, S. Anderson, H. G. Rennke, and B. M. Brenner. 1986. Prevention of diabetic glomerulopathy by pharmacological amelioration of glomerular capillary hypertension. J. Clin. Invest. 77:1925-1930.

28. Marinides, G. N., G. C. Groggel, A. H. Cohen, T. Cook, R. L. Baranowski, C. Westenfelder, and W. A. Border. 1987. Failure of converting enzyme inhibition to affect the course of chronic puromycin aminonucleoside nephropathy. Am. J. Pathol. 129:394-401.

29. Peach, M. J. 1977. Renin-angiotensin system: Biochemistry and mechanisms of action. Physiol. Rev. 57:313-370.

30. Weinstock, J. V., and A. M. Blum. 1983. Isolated liver granulomas of murine Schistosoma mansoni contain components of the angiotensin system. J. Immunol. 131:2529-2532.

31. Campbell, D. J. 1987. Circulating and tissue angiotensin systems. J. Clin. Invest. 79:1-6.

32. Lowe, J. R., J. S. Dixon, J. A. Guthrie, and P. McWhinney. 1986. Serum and synovial fluid levels of angiotensin converting enzyme in polyarthritis. Ann. Rheum. Dis. 45:921-924.

33. Friedland, J., C. Setton, and E. Silverstein. 1978. Induction of angiotensin converting enzyme in human monocytes in culture. Biochem. Biophys. Res. Commun. 83:843-849.

34. Yokosawa, H., Y. Ogura, and S. Ishii. 1983. Purification and inhibition by neuropeptides of angiotensin-converting enzyme from rat brain. J. Neurochem. 41:403-410.

35. Nathan, C. F. 1987. Secretory products of macrophages. $J$. Clin. Invest. 79:319-326.

36. Oliver, J. A., and R. R. Sciacca. 1984. Local generation of angiotensin II as a mechanism of regulation of peripheral vascular tone in the rat. J. Clin. Invest. 74:1247-1251.

37. Farber, H. W., D. M. Center, and S. Rounds. 1985. Bovine and human endothelial cell production of neutrophil chemoattractant activity in response to components of the angiotensin system. Circ. Res. 57:898-902.

38. Johnsen, S. A., and M. Aurell. 1981. Immunosuppressive action of captopril blocked by prostaglandin synthetase inhibitor. Lancet. i: 1005 .

39. Delfraissy, J. F., P. Galanaud, J. F. Balavoine, C. Wallon, and J. Dormont. 1984. Captopril and immune regulation. Kidney Int. 25:925-929.

40. Kallenberg, C. G. M., S. Van der Laan, and D. de Zeevw. 1981. Captopril and the immune system. Lancet. ii:92.
41. Keane, W. F., and L. Raij. 1985. Relationship among altered glomerular barrier permselectivity, angiotensin II, and mesangial uptake of macromolecules. Lab. Invest. 52:599-604.

42. Hoyer, J. R., J. D. Elema, and R. L. Vernier. 1976. Unilateral renal disease in the rat. II. Glomerular mesangial uptake of colloidal carbon in unilateral aminonucleoside nephrosis and nephrotoxic serum nephritis. Lab. Invest. 34:250-255.

43. Ward, D. M., and R. C. Blantz. 1981. Uptake of macromolecules by the glomerular mesangium is increased by angiotensin II. Clin. Res. 29:479. (Abstr.)

44. Grond, J., J. Koudstaal, and J. D. Elema. 1985. Mesangial function and glomerular sclerosis in rats with aminonucleoside nephrosis. Kidney Int. 27:405-410.

45. Gill, G. N., C. R. Ill, and M. H. Simonian. 1977. Angiotensin stimulation of bovine adrenocortical growth. Proc. Natl. Acad. Sci. USA. 74:5569-5573.

46. Campbell-Boswell, M., and A. L. Robertson, Jr. 1981. Effects of angiotensin II and vasopressin on human smooth muscle cells in vitro. Exp. Mol. Pathol. 35:265-276.

47. Emmett, N., and S. Harris-Hooker. 1986. The inhibition of cultured smooth muscle cell growth by saralasin. Fed. Proc. 45:584(2501). (Abstr.)

48. Goodwin, J. S., R. P. Messner, and G. T. Peake. 1978. Prostaglandin suppression of mitogen-stimulated lymphocytes in vitro. $J$. Clin. Invest. 62:753-760.

49. Swartz, S. L., G. H. Williams, N. K. Hollenberg, L. Levine, R. G. Dluhy, and T. J. Moore. 1980. Captopril-induced changes in prostaglandin production: Relationship to vascular responses in normal man. J. Clin. Invest. 65:1257-1264.

50. Galler, M., R. Backenroth, V. W. Folkert, and D. Schlondorff. 1982. Effect of converting enzyme inhibitors on prostaglandin synthesis by isolated glomeruli and aortic strips from rats. J. Pharmacol. Exp. Ther. 220:23-28.

51. Dusing, R., R. Scherhag, G. Landsberg, K. Glanzer, and H. J. Kramer. 1983. The converting enzyme inhibitor captopril stimulates prostacyclin synthesis by isolated rat aorta. Eur. J. Pharmacol. 91:501-504.

52. Baud, L., J. Perez, M. Denis, and R. Ardaillou. 1987. Modulation of fibroblast proliferation by sulfidopeptide leukotrienes: effect of indomethacin. J. Immunol. 138:1190-1195.

53. Baud, L., J. Sraer, J. Perez, M. P. Nivez, and R. Ardaillou. 1985. Leukotriene $C_{4}$ binds to human glomerular epithelial cells and promotes their proliferation in vitro. J. Clin. Invest. 76:374-377.

54. Payan, D. G., A. Missirian-Bastian, and E. J. Goetzl. 1984. Human T-lymphocyte subset specificity of the regulatory effects of leukotriene $\mathrm{B}_{4}$. Proc. Natl. Acad. Sci. USA. 81:3501-3505.

55. Gualde, N., D. Atluru, and J. S. Goodwin. 1985. Effect of lipoxygenase metabolites of arachidonic acid on proliferation of human T cells and T cell subsets. J. Immunol. 134:1125-1129.

56. Simkin, N. J., D. F. Jelinek, and P. E. Lipsky. 1987. Inhibition of human $\mathrm{B}$ cell responsiveness by prostaglandin $\mathrm{E}_{2}$. J. Immunol. 138:1074-1081.

57. Kelly, C. J., R. B. Zurier, K. A. Krakauer, N. Blanchard, and E. G. Neilson. 1987. Prostaglandin $E_{1}$ inhibits effector $T$ cell induction and tissue damage in experimental murine interstitial nephritis. $J$. Clin. Invest. 79:782-789.

58. Owen, N. E. 1985. Prostacyclin can inhibit DNA synthesis in vascular smooth muscle cells. In Prostaglandins, Leukotrienes, and Lipoxins. by J. M. Bailey, editor. Plenum Press, New York. 193-204.

59. Yoshida, Y., A. Fogo, and I. Ichikawa. 1988. Glomerular hypertrophy has a greater impact on glomerular sclerosis than the adaptive hyperfunction in remnant nephrons. Kidney Int. 33:327. (Abstr.)

60. Fogo, A., Y. Yoshida, I. Ichikawa, R. Hoover, and T. Homma. 1988. Angiotensin converting enzyme inhibitor suppresses accelerated growth of glomerular cells in vivo and in vitro. Kidney Int. 33:296. (Abstr.)

61. Homma, T., I. Ichikawa, and R. L. Hoover. 1988. Prostaglandins of mesangium origin inhibit mesangial cell proliferation and matrix synthesis. Kidney Int. 33:268. (Abstr.) 